\title{
A GAMIFICAÇÃO DA NARRATIVA DA TELENOVELA EM VELHO CHICO
}

\author{
Rosângela Fachel de Medeiros ${ }^{1}$
}

Resumo: A morte trágica do ator Domingos Montagner que interpretava o personagem Santo, um dos protagonistas da telenovela Velho Chico (Rede Globo - 2016), criada e escrita por Benedito Ruy Barbosa e dirigida por Luis Fernando Carvalho, a alguns capítulos do final da narrativa, não apenas chocou e colocou em luto o país inteiro como, também, impôs um problema muito grave e concreto à obra. Como manter o personagem que era vivido por Montagner na narrativa? A solução encontrada pela equipe de produção da novela surpreendeu positivamente espectadores e crítica. A câmera até então objetiva e neutra, que assumia um foco ideal através do qual o espectador assiste às cenas de fora, foi substituída por uma câmera subjetiva que assumiu um foco narrativo em primeira pessoa. $\mathrm{O}$ espectador foi então retirado do lugar clássico de observador externo, sendo convidado a assumir o foco narrativo do personagem. A técnica, apesar de não usual, não é uma novidade absoluta e já foi usada, por exemplo, em $A$ dama do lago (1947), Viagem alucinante (2009), e no Brasil em: Eros, o deus do amor (1981) e Viajo porque preciso volto porque te amo (2009). A novidade está em realizar esta ousadia formal em uma narrativa popular, de grande audiência, e obter o engajamento imediato do público à técnica. Nesse sentido, propomos analisar este sucesso a partir da ideia de imersão advinda das narrativas em primeira pessoa dos videogames.

Palavras-chave: Velho Chico. Telenovela. Gamificação.

Abstract: The tragic death of the actor Domingos Montagner who played the Santo character, one of the protagonists of the soap opera Velho Chico (Rede Globo - 2016), created and written by Benedito Ruy Barbosa and directed by Luis Fernando Carvalho, to some chapters at the end of the narrative. Not only shocked and mourned the entire country, but also imposed a very serious and concrete problem to the work. How to maintain the character that was played by Montagner in the narrative? The solution found by the production team of the soap opera surprised viewers and critics. The objective and neutral camera, which assumed an ideal focus through which the viewer watches the outside scenes, was replaced by a subjective camera that took on a first-person narrative focus. The spectator was then removed from the classic place of external observer, being invited to assume the narrative focus of the character. The technique, although not usual, is not an absolute novelty and has already been used, for example, in The Lady of the Lake (1947), Enter the Void (2009), and in Brazil: Eros, the god of love (1981) and I Travel Because I have to, I Come Back Because I Love You (2009). The novelty is to realize this formal boldness in a popular narrative, of great audience, and to obtain the immediate engagement of the public to the technique. In this sense, we propose to analyze this success from the idea of immersion coming from the first-person narratives of videogames.

Keywords: Velho Chico. Soap opera. Gamification.

\footnotetext{
${ }^{1}$ Doutora em Literatura Comparada pela UFRGS, professora do Mestrado em Letras - Literatura Comparada - URI/FW. E-mail: fachel@fw.uri.br
} 
A telenovela Velho Chico foi realizada pela Rede Globo e teve um total de 173 capítulos, indo ao ar de segunda à sexta, no horário das $21 \mathrm{~h}$, de 14 de março a 30 de setembro de 2016. A trama criada por Benedito Ruy Barbosa e Ednara Barbosa e escrita por Ruy Barbosa e Bruno Luperi, com a colaboração de Luis Alberto de Abreu, girava em torno da saga de rivalidade entre duas famílias que vivem na cidade fictícia de Grotas de São Francisco, localizada as beiras do Rio São Francisco. Os tons de tragédia se anunciam quando a rivalidade é atravessada pela história de amor proibida entre Santo e Maria Tereza, integrantes das famílias rivais. A trama familiar shakespeariana, como a define o próprio Ruy Barbosa, que tem como pano de fundo uma crítica à desigualdade social enraizada na cultura e na política brasileira, transcorre às margens do Rio São Francisco, o Velho Chico que dá nome a história. Presença constante na narrativa e na vida dos personagens, o rio acaba se configurando como protagonista da trama em vários episódios: foi no rio que morreu o primogênito da família de fazendeiros e foi, também, em suas águas que Santo e Maria Tereza se conheceram e nestas mesmas águas viveram tórridas cenas de amor, e foi justamente nestas águas que Santo, personagem vivido por Domingos Montagner, desapareceu e quase morreu. Na máxima mais clichê e triste, a vida imitou a arte, e foi nas águas do Rio São Francisco que o Montagner acabou por perder a vida, a duas semanas do final da narrativa.

Enquanto uma realização coletiva, a telenovela além de um grupo de autores, coordenados por Rui Barbosa, era igualmente dirigida por um grupo de direção formado por Carlos Araújo, Gustavo Fernandez, Antônio Karnewale, Philipe Barcinski e Luiz Fernando Carvalho, este também diretor artístico, que tiveram então de conjuntamente decidir em pouquíssimo tempo como finalizar a novela. Qual seria o desfecho possível para um personagem protagonistas cujo intérprete morre faltando a gravação de apenas algumas cenas? No sábado, dia 17 de setembro, dois dias após a trágica morte do ator, a Rede Globo lança um comunicado oficial a respeito da decisão em relação à continuidade da telenovela:

Em homenagem ao ator Domingos Montagner e ao grande trabalho realizado por ele na construção de Santo, a direção de Velho Chico montou uma estratégia para continuar contando a história como estava planejado, sem criar uma trama diferente da prevista para o personagem [...] Santo dos Anjos 
estará presente em todas as suas cenas e o seu olhar será visto por todos os que assistem à novela (VELHO CHICO, 2016).

Sem esclarecer como o fará, a Rede Globo garante que o personagem estará presente em todas as cenas que haviam sido planejadas e dá uma única pista: "seu olhar será visto por todos que assistem à novela". A novela seguiu seu curso, mantendo a exibição dos episódios que já haviam sido gravados. A última cena gravada por Montagner foi ao ar no dia 24 de setembro, nove dias após sua morte. Foi então na segunda-feira, 26 de setembro, da última semana de exibição da telenovela, que o mistério em relação à permanência do personagem Santo na trama foi revelada. Dentre as possibilidades elencadas para seguir com 0 personagem e com a sua participação na telenovela, a equipe optou pela que narrativamente talvez fosse uma das mais perigosas, utilizar uma câmera subjetiva para assumir o foco narrativo de Santo e, assim, substituir Montagner nas cenas. Para Benedito Ruy Barbosa:

O resultado, estético, ficou muito bonito. É uma singela homenagem [...] Na direção, eles tiveram a possibilidade de dilatar um pouco o tempo de fala. Os atores estão curtindo muito olhar para a câmera, falar com a câmera, interpretarem em outro tempo. As luzes também estão diferentes. Está sublime. Não é nada lúgubre, pesado. É uma homenagem à vida (STYCER, 2016).

O espectador já não vê mais o ator que incorpora o personagem, mas passa a ver, ouvir e "sentir" tudo o que esse personagem vivencia em cada cena. Um dos aspectos mais importantes para construir a verossimilhança do subterfúgio foi a atuação dos demais atores/personagens, que tiveram de interagir e atuar com a câmera/personagem, olhando e falando diretamente para a lente da câmera como se fosse para o rosto de Santo. E no mesmo sentido, foi preciso que a câmera contracenasse com os atores, exigindo também um trabalho diferenciado do fotógrafo e cinegrafista, Leandro Pagliaro, como faz questão de salientar o jovem ator Gabriel Leone, que interpretava Miguel, filho de Santo e Tereza na telenovela: 
É um câmera que trabalha com o Luiz [Fernando Carvalho] há muito tempo, que trabalha com a gente em Velho Chico desde o início, conviveu muito com ele [Domingos Montagner], gravou muito com ele. Então, o Leandro tem essa grande responsabilidade de estar sendo, não só os olhos dele, mas o sentimento dele, se relacionando, contracenando com a gente (ELENCO, 2016).

Bento (interpretado por Irandhir Santos) olha diretamente para a câmera e começa a falar "É, mano velho", a câmera faz movimentos curtos e mais evidentes do que o habitual, simulando os movimentos do corpo humano e escutamos em alguns momentos a voz de Santo/Montagner. E, aos poucos, sem precisar de explicação alguma, o espectador se dá conta de que está no lugar do personagem, vendo, escutando e sentido o que ele vivencia. Frases ditas por Santo/Montagner em cenas anteriores, bem sons de sua respiração e de sua risada, são encaixadas nas novas cenas, sendo usadas para completar e dar mais credibilidade a construção narrativa. Além disso, são utilizados recursos técnicos de foco e lentes não apenas para diferenciar o olhar de Santo em relação ao que é mostrado pela câmera objetiva do restante da narrativa, mas, principalmente, para fazer com que os espectadores pudessem ler naquelas imagens, as emoções sentidas pelo personagem. O espectador já não podia ver os olhos marejados de Santo, mas pode ver a imagem como se fora vista por olhos marejados.

Da mesma forma, a câmera teve de assumir um novo ritmo de movimentos simulando o caminhar e a movimentação da cabeça do personagem. O balé entre a câmera e os personagens, inerente ao ambiente de gravação da telenovela, passa a ter uma nova perspectiva e a coreografia clássica que tinha por função evitar que o espectador tivesse consciência da presença da câmera na cena passa, justamente, a buscar o contrário, é preciso que o espectador se dê conta da presença da câmera e, principalmente, que a assuma enquanto personagem e parte ativa da narrativa. $A$ importância da câmera para as cenas foi destacada pelo ator Gabriel Leone: "A câmera estava completamente viva. Era como ele estaria em cena com a gente no nosso casamento, numa alegria, numa felicidade. Foi muito bonito!" (ELENCO, 2016).

E tudo isso com um agravante inerente à própria configuração e à linguagem da telenovela de ser uma narrativa marcada pelos diálogos e pelos closes nos rostos 
do atores/personagens. Em contraponto ao personagem/câmera sem rosto e quase sem voz, seus coadjuvantes são mostrados em closes fechados que preenchem a tela e destacam a emoção transparente nos rostos dos demais personagens/atores. Além disso, estamos falando de um dos produtos audiovisuais mais populares da televisão brasileira, realizado pela maior produtora de telenovelas do país (Rede Globo) e apresentado em seu horário mais nobre, 21h, que é alicerçado por repertórios narrativos e estéticos estabelecidos e reconhecidos pelos espectadores. Ou seja, a proposta ousada decidida, em pouco tempo, poderia por a perder a audiência da narrativa.

\section{Do ator-personagem ao espectador-personagem}

Um dos pontos mais importantes para o sucesso de uma telenovela é a repercussão de seus personagens na audiência, seja positiva ou negativamente, quanto maior, maior será o impacto da telenovela e isto sempre está relacionado ao trabalho dos atores. Na história da telenovela brasileira são muitos os exemplos de atores que ficaram para sempre marcados e lembrados pela forma como incorporaram algum personagem. E, com certeza, durante o tempo de duração da telenovela atores em papeis de destaque serão reconhecidos por seus personagens e, não poucas vezes, sendo identificados como seus personagens. Há poucos anos atuando na televisão, vindo de uma formação teatral e circense, Montagner foi um daqueles casos raros de acolhimento instantâneo pelo público desde sua estreia na telenovela Cordel Encantado (2011), Velho Chico era sua quarta novela e Santo, seu segundo protagonista. A empatia do público com o personagem Santo, vivido por Montagner, era notória, um dos episódios de maior audiência da produção foi, justamente, a que revelava o desaparecimento de seu personagem no rio São Francisco. Tanto que foi quase impossível aos espectadores relacionarem a ligação entre o personagem e o rio São Francisco, bem como o episodio de seu desaparecimento no rio e posterior resgate por índios, à tragédia que ceifou sua vida. Revela-se assim, o sucesso absoluto da interpretação na composição do personagem, que se tornou tão real quanto o próprio ator. Como então manter a vida do personagem, após a morte do ator que o incorporava? Parece que a escolha da equipe da novela foi trazer o espectador para o papel de Santo, confiando na 
empatia da audiência com o personagem para garantir sua imersão no universo narrativo e assumir e aceitar esta nova perspectiva narrativa.

\section{Câmera subjetiva e foco narrativo}

Apesar de pouco usual a utilização da câmera subjetiva não é uma novidade. No cinema, ela foi apresentada pela primeira vez no filme $A$ dama do lago (Lady in the Lak - 1947), de por Robert Montgomery, um policial noir, que além de ser narrado em primeira pessoa pelo protagonista, o detetive Philip Marlowe, apresenta todas as cenas através de seu ponto de vista. A MGM, produtora do filme, apresentava essa perspectiva narrativa como algo revolucionário, afinal 0 espectador estaria desvendando o caso conjuntamente ao personagem. Mais recentemente e com uma tecnologia muito mais apurada, Viagem alucinante (Enter the Void - 2009), de Gaspar Noé, traz para a tela o ponto de vista de seu protagonista, o traficante de drogas Oscar, cujo espírito, após ser morto pela polícia, recusa-se em deixar a terra. No mesmo ano, o premiado filme brasileiro, Viajo porque preciso volto porque te amo (2009), de Karim Aïnouz e Marcelo Gomes, também utiliza o subterfúgio da câmera subjetiva para contar a história de solidão do geólogo José Renato enquanto ele viaja a trabalho para uma isolada região do nordeste brasileiro. Mas em 1981, ainda antes disso, em 1981, no filme Eros, o deus do amor, Walter Hugo Khouri já utilizara a câmera subjetiva. Em todos os quatro exemplos, a câmera subjetiva assume o foco narrativo de um personagem, que, de maneira geral, conduz a narrativa do filme. A pontualidade destas experiências cinematográficas serve para destacar o fato de que este subterfúgio narrativo, apesar de já usado anteriormente, não é algo recorrente, estando mais confortável no campo do cinema, no qual são permitidos maiores riscos referentes à narrativa e à linguagem. Mas como então o artifício da câmera subjetiva funcionou tão bem e foi completamente aceito e entendido pelos espectadores? Nossa hipótese é que a compreensão desta perspectiva narrativa tenha derivado do contato direto e indireto com as narrativas audiovisuais em primeira pessoa do videogame. 


\section{Narrativas em primeira pessoa - dos videogames à telenovela}

Os Jogos em Primeira Pessoa (FPS games) são assim denominados por conta de sua interface gráfica que apresenta e segue o foco narrativo do personagem controlado pelo jogador, essa perspectiva narrativa é muito usada e tem muito impacto em jogos com armas de fogo, jogos de atiradores (shooters em primeira pessoa), os quais são reconhecidos como os primeiros a utilizar essa perspectiva. No entanto, narrativas em primeira pessoa estão cada vez mais presente nos mais variados gêneros de jogos: corridas, simuladores de voo, jogos de aventura. Para ingressar em um jogo em primeira pessoa, o jogador assume a identidade de um avatar (que será o seu personagem) através do qual ele adentra o universo diegético da narrativa. A tela constitui-se então como a interface na qual se desenvolve o jogo para onde confluem a narrativa criada pelo sistema e os comandos realizados pelo jogador através de seu avatar. Ao estar em um jogo em primeira pessoa, o jogador não enxerga o próprio avatar, apenas pode ver as partes de seu corpo que seria visíveis aos olhos de seu avatar, como mãos e pernas. Para criar a perspectiva sonora do espaço que é percorrido e explorado pelo avatar, é usado o áudio posicional, que faz com que a intensidade dos sons varie conforme a posição do avatar em relação às fontes sonoras no jogo. A perspectiva em primeira pessoa vem se tornando mais complexa à medida que evoluem as tecnologias dos jogos em 3D, uma vez que nestes o jogador se sente imerso no espaço diegético da narrativa, contrário dos outros em que é apenas o foco do olhar o mantém ligado à narrativa.

A câmera subjetiva do cinema ganha nova roupagem ao ser imbricada a perspectiva da narrativa em primeira pessoa advinda do campo dos videogames. Estamos entrando na era dos filmes em primeira pessoa (FPS Movies); o primeiro e mais notório experimento é o recente Hardcore: missão extrema (Hardcore Henry 2015), de llya Naishuller, é uma obra de ficção científica que conta a história de Henry, um ciborgue ressuscitado por sua esposa/criadora, que deve lutar para salvála de um tirano. O filme não apenas apresenta quase que toda a narrativa sob a perspectiva em primeira pessoa de Henry, mas, também, se apropria de toda a estética e da linguagem narrativa dos videogames. No entanto, ao contrário de 
outras obras que adaptaram narrativas de videogames para o cinema, Hardcore não está baseado em nenhum jogo específico, mas traz para o cinema a linguagem do videogame. É nesse sentido, pensamos na gameficação da narrativa cinematográfica e, consequentemente, na gamificação da telenovela.

\section{A Gamificação da telenovela}

O conceito de gamificação surge para identificar o processo cada vez mais frequente da apropriação e utilização de repertórios, elementos, mecanismos, dinâmicas e técnicas de games - por outras áreas. De maneira geral, o conceito vem sendo muito aplicado nas áreas da educação e do marketing como uma estratégia para a criação de mecanismos e métodos baseados nos videogames, que possam otimizar o processo de aprendizado e venda, respectivamente. No entanto, o que nos interessa aqui é identificar a gamificação como uma ação natural e espontânea decorrente da interferência, da influência e do convívio transmidiático entre as linguagens. Ou seja, quando a equipe de Velho Chico decide usar uma câmera subjetiva para manter a presença do personagem Santo na trama, não houve uma intenção consciente de gamificar a narrativa, mas a influência da narrativa do videogame estava

\section{Gamificação como Imersão}

Um dos fatores mais importantes para o sucesso de um videogame é o seu potencial de imersão, a capacidade que a narrativa possui de fazer com que seu jogador se sinta envolvido por uma outra realidade capaz de prender toda a sua atenção e todo seu aparato de percepção. Conforme Emmanoel Ferreira, em seu artigo "Paradigmas do jogar: Interação, corpo e imersão nos videogames", todas as definições de imersão rumam para um denominador comum, a "sensação de presença numa outra realidade" (2009). Em outro artigo, Ferreira e Oliveira (2011) apresentam a classificação dos tipos de imersão conforme definida por Laura Ermi e Frans Mäyra, no contexto específico do videogame: imersão imaginada, imersão baseada em desafios e imersão sensorial. A imersão imaginada relaciona-se ao engajamento do jogador com o conteúdo diegético da narrativa. A imersão baseada 
em desafios corresponde ao envolvimento do jogador para vencer os desafios lúdicos apresentados pela narrativa. A imersão sensorial, mais relacionada à capacidade técnica do suporte do jogo, diz respeito ao envolvimento do jogador com a trama decorrente das sensações audiovisuais e táteis proporcionadas pela narrativa (gráficos e trilha sonora).

$\mathrm{Na}$ perspectiva de Velho Chico poderíamos dizer que ocorre a imersão imaginada, decorrente do engajamento do espectador com o conteúdo diegético (visual e temático) da narrativa. O espectador rapidamente compreendeu 0 subterfúgio narrativo e assumiu seu papel de protagonista em primeira pessoa na pele de Santo. Imediatamente à exibição das primeiras cenas do capítulo começaram as declarações comovidas dos espectadores nas redes sociais: "A lente reflete o artista e a emoção de cada personagem"; “... me emocionei e chorei de ver uma câmera como se fosse ele [Montagner] com uma voz lá no fundo bem suave" (DEL RE, 2016) Ao aceitar a perspectiva em primeira pessoa da narrativa e assumir que tem acesso às imagens, falas, sensações e emoções através do olhar de Santo, o espectador mergulha na narrativa, se deixando envolver pelo universo da trama e assumindo-o como verossimilhança.

O êxito na utilização da câmera subjetiva na configuração de uma nova perspectiva narrativa para a telenovela revela que há um novo espectador frente às telas pronto para novos desafios para os quais, no entanto, os produtores e realizadores talvez ainda não estejam prontos. Pode ser que esteja acontecendo uma inversão na máxima de que a percepção dos artistas em relação ao mundo e às suas transformações sempre esteve à frente da percepção do público, mas isso, por enquanto, ainda é apenas especulação.

\section{REFERÊNCIAS}

DEL RE, Adriana. Câmera subjetiva substitui Domingos Montagner em "Velho Chico" e emociona público. Cultura. Estadão. São Paulo. 27 de set. 2016.

Disponível em: http://cultura.estadao.com.br/blogs/radar-cultural/camera-subjetivasubstitui-domingos-montagner-em-velho-chico-e-emociona-publico/

Acessado em: 03 de mar. 2017. 
Elenco e autor de 'Velho Chico' comentam sobre câmera subjetiva. UAl. Estado de Minas. 28 de set. 2016. Disponível em: http://www.uai.com.br/app/noticia/series-etv/2016/09/28/noticias-series-e-tv, 194932/elenco-e-autor-de-velho-chico-comentamsobre-camera-subjetiva.shtml Acessado em: 03 de mar. De 2017.

'VELHO CHICO' segue sua história como homenagem ao ator Domingos Montagner. GSHOW. Globo.com. 17 de set. 2016.

Disponível em: http://gshow.globo.com/tv/noticia/2016/09/velho-chico-segue-suahistoria-como-homenagem-ao-ator-domingos-montagner.html Acessado em 03 de mar. 2017.

FERREIRA, Emmanoel. Paradigmas do jogar: Interação, corpo e imersão nos videogames. In: VIII Brazilian Symposium on Games and Digital Entertainment. Rio de Janeiro, RJ - Brazil, 2009. Disponível em:

http://www.sbgames.org/papers/sbgames09/culture/full/cult26 09.pdf. Acessado em 03 de mar. 2017.

FERREIRA, Emmanoel; OLIVEIRA, Thaiane. Som, imersão e jogos eletrônicos: um estudo empírico. In: SBC - Proceedings of SBGames, 2011.

Disponível em:

http://www.sbgames.org/sbgames2011/proceedings/sbgames/papers/cult/short/9225 0 1.pdf. Acessado em: 03 de mar. de 2017

STYCER, Maurício. Público enxerga com olhos de Santo em linda homenagem a Domingos Montagner. Blog do Maurício Stycer. Blogosfera. UOL. 26 de set. de 2017. Disponível em:

http://mauriciostycer.blogosfera.uol.com.br/2016/09/26/publico-enxerga-com-olhosde-santo-em-linda-homenagem-a-domingos-montagner/ Acessado em: 03 de mar. De 2017 